\section{Brain white matter lesions correlated to newborns death and lethality}

\section{Fatores correlacionados ao óbito e à letalidade hospitalar em neonatos com lesão da substância branca cerebral}

Nayara Argollo 1

Ines Lessa 2

Suely Ribeiro 3

Katiusha C. Abreu 4

Juliana M.S.Pinto 5

Raquel P. Faria 6

Tatiana G. Telles 7

Gabriel Santos 8

\section{Abstract}

Objectives: to describe hospital lethality rates and factors correlated to death in neonates with brain white matter lesions.

Methods: a retrospective study was performed from January 1994 to December 2001. Neonates with white brain matter lesions were divided into survival and death groups and their medical files reviewed through the single blind method to determine evolution. Death certificates provided the cause of death. The groups were compared through correlation coefficients. Hospital lethality rate was calculated.

Results: ninety three cases of white brain matter lesions and seven deaths were determined. Hospital lethality rate was of 8.2.\% (95\% CI: 2.4-14.0) independently from lesion occurrence time, and of $10.3 \%$ (95\%CI: 3.3-17.3) for deaths occurred during prenatal and perinatal periods. Death was correlated to: Apgar score, non-cephalic presentation, gestational age, hyperglicemia, hypercalcemia, convulsion, respiratory insufficiency and atelectasy.

Conclusions: hospital lethality was of $10.3 \%$ generating the following hypothesis: perinatal asphyxia must be the principal direct and indirect etiologic factor (aggravating the expression of prematurity and infection diseases), of prenatal and perinatal mortality among newborns with white brain matter lesions; and $<7$ Apgar score in the $5^{\text {th }}$ minute associated to brain white matter lesions, are markers for perinatal asphyxia diagnosis.

Key words Brain diseases, Cerebral infarction, Apgar score, Infant mortality

\section{Resumo}

Objetivos: descrever a taxa de letalidade hospitalar e fatores correlacionados com o óbito em crianças com lesão da substância branca cerebral (LSB).

Métodos: estudo retrospectivo realizado de janeiro de 1994 a dezembro de 2001. Os neonatos com LSB foram divididos em sobreviventes ou óbito, $e$ seus prontuários revisados de forma cega para a evolução. Dos atestados de óbito, a causa de morte. Os grupos foram comparados por coeficientes de correlação. Calculada a taxa de letalidade hospitalar.

Resultados: foram encontrados 93 casos de LSB e sete óbitos. A taxa de letalidade hospitalar foi de 8,2\%, (IC95\%: 2,4-14,0), independentemente da época de instalação da lesão, e de 10,3\% (IC95\%: 3,3-17,3) para aqueles de ocorrência pré/perinatal. O óbito correlacionou-se com: escore de Apgar, apresentação não-cefálica, idade gestacional, hiperglicemia, hipercalcemia, convulsão, insuficiência respiratória e atelectasia.

Conclusões: a letalidade hospitalar foi de 10,3\% $e$ as seguintes hipóteses foram geradas: a asfixia perinatal deve ser o principal fator etiológico, direto e indireto (agravando a expressão das doenças da prematuridade e da infecção), da mortalidade pré/perinatal entre neonatos com LSB; e o escore de Apgar do 50 minuto $<7$, associado à LSB, são marcadores para o diagnóstico de asfixia perinatal.

Palavras-chave Doenças cerebrais, Infarto cerebral, Índice de Apgar, Mortalidade neonatal 


\section{Introduction}

Perinatal deaths account for $56.8 \%$ of all infant deaths in Brazil. ${ }^{1}$ and birthweight is the higher predictor of morbidity and mortality in the first year of life ${ }^{2}$ particularly, in the neonatal period: lower birthweight results in higher perinatal morbidity and mortality.

Intrauterine growth retardation and prematurity are the two main causes of low birthweight $(<2500$ g). In Brazil $50 \%$ of the newborns with low birthweight are premature ${ }^{3}$ and among these, the risk for child mortality is 2.5 times higher than in newborns that are small in relation to gestational age and 13 times higher than in newborns with adequate birthweight. 3,4

Premature neonates'deaths are secondary to immature physiology with "perinatal death causes" playing a prevalent role. The association of physiological immaturity, ischemic hypoxia events (perinatal asphyxia, apnea with hypoxia, bradicardy, hyaline membrane condition, and cardiac diseases) and intrauterine infections are important causes for premature neonate mortality and etiological factors of the principal brain lesion in neonates: white matter lesion.

The two predominant types of white brain matter lesions are - hemorrhagic preventricular infarction and periventricular leukomalatia - can be determined through cranial ultrasonography through echodensity visualization. Periventricular leukomalatia and periventricular hemorrhagic infarction are neuropathological diagnosis, while echodensity and echolucency are descriptive ultrasonographic terms for these lesions. Abnormalities patterns of USc are heterogeneous and many times difficult to distinguish between the two types of lesions. Therefore, the term "prematurity white matter lesion" is preferable when describing ultrasonographic abnormalities of this region in premature neonates. 5

White brain matter lesions in premature neonates ( 23 weeks to 32 weeks), and indirectly of the fetus represent the highest predictor of cerebral palsy, mental retardation, visual, cognitive and behavioral problems in the future. Nevertheless, in contrast with the extensive literature on the long term prognosis of neonates with white matter lesions, very little has been published on hospital lethality and its causes in neonates with the same pathology. To know the causes of early and late lethality in neonates with white brain matter lesions, independently from gestational age, will offer information to the Obstetrician and Neonatologist on death's risk factors, will support decision making on early inter- ventions in high risk pregnancies in addition to alert Neonatologists to anticipate and introduce preventive and curative methods for these risk factors.

The objectives of this article are to determine hospital lethality rates in children with white brain matter lesions and generate hypothesis on the risk factors of death caused by this pathology.

\section{Methods}

A retrospective, correlated study, performed in the main reference hospital for high risk pregnancies among health insured and private patients. The annual number of deliveries ( 2900) is high and the maternity wards hold the largest number in neonatal intensive care units (ICU) in the State of Bahia in Brazil. Cranial ultrasonography is systematically performed in all newborns admitted in the neonatal ICU in the first three days, in the seventh, fourteenth and twenty first day following birth or any clinical event. All cranial ultrasound exams are performed by a specialized neonatologist with ample experience in neonates.

Through cranial ultrasound exams reports, neonates with signs of brain white matter lesions were identified, with or without intraventricular hemorrhage, hydrocephaly or ventriculomegaly, born between January 1994 and December, 2001. The medical files of this group of neonates were reviewed by a single blind method to the death outcome and data related to pregnancy, delivery, neonatal period, clinical events and complementary exams were registered by the researchers KA, RF and GS. Medical files were entered for: a) information related to pregnancy, serology and reason for early pregnancy interruption or Cesarean section, written in the anamneses, systematically performed by the Neonatologist to the Obstetrician in the delivery room; b) gestational age based on the last menstruation date and menstruation absence, Capurro score; c) Apgar score in the $1^{\text {st }}$ and $5^{\text {th }}$ minutes; d) birthweight; e) diagnosis, problems and intercurrences during hospital stay; f) complementary exams results, analyzed based on the normal variation for the age group; and g) discharge report data and death certificates written by another researcher (NA). A total of 51 variables were listed (day of birth, sex, maternal age, type of delivery, type of presentation, gemelarity, number of twins, gestational age based on Capurro, oligohydramnios, eclampsy, pre-eclampsy, arterial hypertension during pregnancy, early membranes rupture, placenta abruption, ascending infection, diagnosed or 
suspected by the Obstetrician, fetus removal difficulty, other gestation complications, Apgar score in the 1 st, $5^{\text {th }}$ and $10^{\text {th }}$ day, birthweight, hypoglicemia, hyperglicemia, jaundice, hyponatremia, hypernatremia, prematurity of osteopaenia, hypopotasemia, other metabolites disorder, asphyxia diagnosis by the Neonatologist, apnea, infection, convulsion, retinopathy, Ck-mb dosage, hospitalization time, death, death cause, other complications of the neonatal period, USc descriptive alteration, lesion time, anatomic and pathological exam of the placenta.

Variables were transformed into dichotomic (yes/no or present/absence). Birthweight was classified into: $<500 \mathrm{~g} ; 501 \mathrm{~g}-999 \mathrm{~g} ; 1000 \mathrm{~g}-1499 \mathrm{~g} ; 1500$ g-2000 g; 2001-2499 g; and $\geq 2500$ g. Prematurity degree into: $<32$ weeks, 32 weeks to 33 weeks and six days; 34 weeks to 36 weeks and six days. Neonates between 37 weeks to 41 weeks and six days were considered at term neonates.

Classification for white matter lesion: increased echodensity (in the periventricular regions); and complication: echolucency and/or echodensity complicated with ventriculomegaly (and/or colpocephaly) and/or hydrocephaly (with or without intraventricular hemorrhage). This classification avoids anatomic and pathogenic terms of periventricular leukomalatia and periventricular hemorrhagic infarction pathologies which are difficult to differentiate in terms of USc, 5 severeness is rated according to brain mass loss, increased echodensity (edema without signs of brain tissues loss), echolucency (focal secondary necrosis to leukomalatia or periventricular hemorrhagic infarction). Both could evolve to complications such as atrophy (ventriculomegaly, indirect signal of brain tissue loss) or white matter compression (hydrocephaly, hemorrhage). To be placed into specific groups the worse result of a series of ultrasound performed on the neonate was determined. The time of lesion occurrence was divided into: antenatal, when periventricular echolucency was immediately present a few hours following birth; and postnatal when ultrasound alterations appeared following a known clinical event. ${ }^{6}$

Cases were broken into two groups: the one resulting in death and the survival group. Eight neonates that had been transferred from another hospital or any other hospital due to incomplete information on pregnancy and delivery were excluded. Malformation syndromes, congenital infections or alterations of the screening test extended to metabolic innate errors.

Only the survival group (17 neonates - $20 \%$ of the survival group) had cases of postnatal brain white matter lesion, none in the resulting death group. The survival group should be perceived as a specific neonate group, in which postnatal injury did not compromise neonates'survival, therefore, this sub-group within the survival group was removed from the analysis to enable comparison between prenatal and perinatal injuries. Thus, the group resulting in death (the "death" group comprised seven cases and the ones who survived ("survival group"), 61 cases.

Two hospital lethality rates were calculated (confidence interval at 95\%) for neonates with brain white matter lesion: the denominator represented for all pathology cases noted in the study period, and afterwards, excluded the postnatal injury ones and the transferred ones; the numerator in both was the number of deaths caused by the lesion of the brain white substance itself in the same period. Medians with standard deviations and medians with variations were obtained for all quantitative variables. To assess similarity the subgroups were compared among themselves through non-parametric statistical tests: Mann-Whitney, for quantitative variables and Chi-Square (Fisher) for qualitative variables. Correlations between groups were accomplished by the Spearman $(r)$ (quantitative variables) ETA $(\varepsilon)$ (nominal variables x quantitative variables) and PHI (ö) (between dichotomic variables) methods. All variables with the correlation value of $p<0.05$ were ponderated through Binary Logistic Regression (forward stepwise) to determine independent predictors. The value $\mathrm{p}<0.05$ was considered significant.

The project was approved by the Research Ethics Committee of the Maternity Hospital Climério de Oliveira, Post-Graduate Course in Medicine and Health of the Federal University of Bahia.

\section{Results}

During the period studied $93(3.46 \%)$ cases of white brain matter lesion were determined among the 2688 cases admitted in the Neonatal ICU, 8 (8.6\% of the total of brain white matter lesion) were transferred and excluded. Of the total of 85,7 evolved to death, with a hospital lethality rate of $8.2 \%$ (95\% CI: 2.414.0) independently from the time the lesion occurred. Nevertheless, hospital lethality considering the prenatal and perinatal brain white matter lesion was of $10.3 \%$ (95\%CI: 3.3-17.3). Of the 25 excluded cases ( 8 transferred and 17 with postnatal lesion) the median mothers'age (26.59 years old), of gestational age (30.79 weeks), birthweight (1360.87 g) and the low birthweight proportion (92\%) and female sex $(60 \%)$ showed no significant statistical 
Tabela 1

\begin{tabular}{|c|c|c|c|}
\hline Characteristics & Death Group $(n=7)$ & Survival Group $(n=61)$ & $p$ value \\
\hline Maternal age (years), $\bar{x} \pm d p$ Median & $31.2 \pm 6.83$ & $28.14 \pm 6.06$ & 0.2113 \\
\hline (variation) & $33(20$ a 37$) 1$ & $29(15-41)^{2}$ & \\
\hline Gestational age (weeks), $\bar{x} \pm d p$ Median & $32.27 \pm 5.52$ & $31.57 \pm 3.94$ & $0.777^{3}$ \\
\hline (variation) & $34.30(25-38.1)$ & $31.000(24-40)$ & \\
\hline Female sex (\%) & $4(57.14)$ & $32(52.46)$ & 0.1004 \\
\hline Low birthweight & $7(100.0)$ & $53(86.9)$ & 0.5874 \\
\hline Hospitalization (days), $\bar{x} \pm$ dp Median & $23 \pm 16.21$ & $43.87 \pm 36.71$ & 0.0273 \\
\hline (variation) & $23(3$ a 44$)$ & $49.98(4-225)$ & \\
\hline
\end{tabular}

1) $n=5$;2) $n=56$; 3) Mann Whitney test; 4) Chi-Square test (Fisher).

Tabela 2

Time of appearance and type of lesion of the brain white matter.

\begin{tabular}{|c|c|c|c|c|}
\hline \multirow[t]{2}{*}{ Group 1} & \multirow[t]{2}{*}{ Type of brain white matter lesion } & \multicolumn{2}{|c|}{ Time of insult } & \multirow[t]{2}{*}{ Total $(\%)$} \\
\hline & & Prenatal (\%) & Perinatal $(\%)$ & \\
\hline Survivors & Increased echodensity & $1(1.64)$ & $38(62.30)$ & $39(63.90)$ \\
\hline$(n=61)$ & Aggravated & $4(6.56)$ & $18(29.51)$ & $22(36.10)$ \\
\hline Total & & $5(8.20)$ & $56(91.80)$ & $61(100.0)$ \\
\hline Death & Increased echodensity & $0(0.0)$ & $4(57.14)$ & $4(57.14)$ \\
\hline$(n=7)$ & Aggravated & $1(14.29)$ & $2(28.57)$ & $3(42.85)$ \\
\hline Total (\%) & & $1(14.29)$ & $6(85.71)$ & $7(100.0)$ \\
\hline
\end{tabular}

1 - Chi-Square test (Fisher): Group x Type of brain white matter lesion $p=0,702$; Group $\mathrm{x}$ Time of insult $p=0.493$.

Tabela 3

Correlation between gestational complications/ patterns and neonate death.

\begin{tabular}{lccc}
\hline Death x characteristics / pathology & Correlation Coefficient PHI (ö) & Correlation & $p$ value \\
\hline Oligohydramnios & -0.176 & Weak & 0.147 \\
Polihydramnios & -0.059 & Weak & 0.627 \\
Eclampsy & -0.041 & Weak & 0.733 \\
Pre-eclampsy & -0.149 & Weak & 0.220 \\
Maternal arterial hypertension & -0.122 & Weak & 0.316 \\
Pregnant women urinary tract infection & -0.073 & Weak & 0.548 \\
Gemeparity & -0.085 & Weak & 0.485 \\
Other pregnancy complications & -0.427 & Moderate & 0.576 \\
\hline
\end{tabular}


Perinatal and delivery characteristics/complications with significant statistical correlation between death and survival groups.

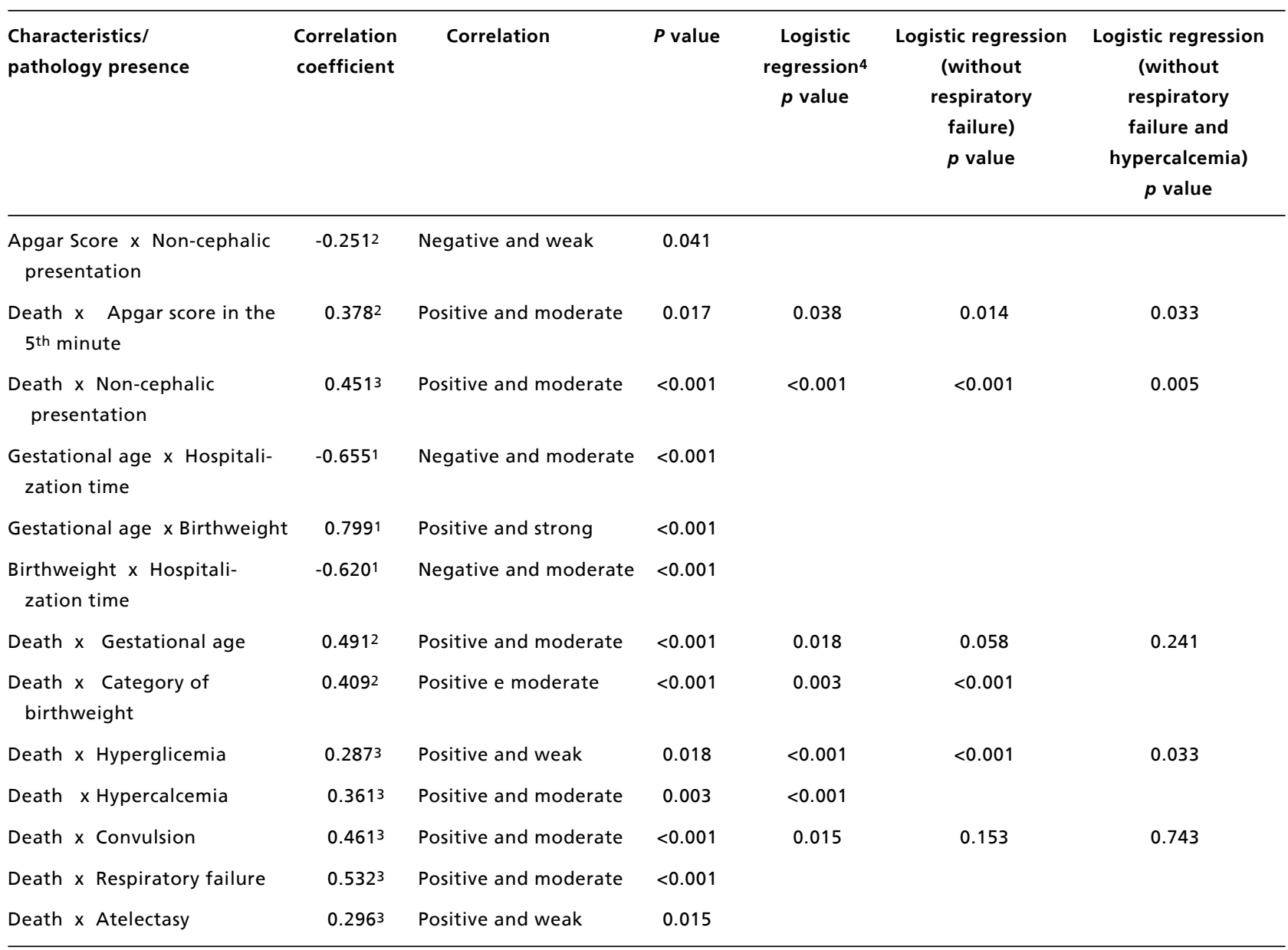

1) Spearman correlation coefficient $(r) ; 2)$ ETA Correlation Coefficient ( $\varepsilon$ ); 3) PHI (ö) Correlation Coefficient; 4) Logistic Regression (Forward stepwise).

difference from the non-excluded group (Chi-Square test for sex and low birthweight with $p=0.544$ and 0.721 respectively and Mann-Whitney with $p=$ 0.283 and 0.264 for maternal age and gestational age respectively).

Table 1 shows that the ones who died were similar to the ones who survived as related to maternal age, gestational age, low birthweight and female sex predominance $(p>0.05)$. The number of hospitalization time was lower than in the group evolving to death $(p=0.027)$. Death occurred up to 60 days in the hospital in seven cases, while among the surviving cases, $95 \%$ were hospitalized up to 90 days. Maternal age was not found in the medical files in seven of the cases (five in the "survival" and two in the "death" groups). In the "death" group, a neonate had no Apgar score registered and in two of them birthweight had not been registered.

The type of predominant alteration found in the ultrasound exam was echodensity and the time of appearance concentrated in the perinatal period and not statistically different between the two groups (Table 2).

Correlation analysis between the two groups (Table 3) did not show significance for illnesses of the gestational history (oligohydramnios, polihydramnios, eclampsy, pre-eclampsy, maternal hypertension, infection of the urinary tract in pregnant women, gemeparity, and other complications).

As for the events occurring during delivery the 
Apgar Score in the $5^{\text {th }}$ minute was lower in the "death" group (6.17 versus 8.15$)$ with positive correlation coefficient of 0.378 (moderate) (Table 4). In this group there were more deliveries with noncephalic presentation ( $71.43 \%$ versus $13.12 \%$ ) with moderate correlation ( $\ddot{o}=0.451)$. These differences were statistically significant in contrast with the lack of statistical significance of the differences between: asphyxia reports, fetal suffering, placenta abruptio, premature membrane rupture, ascending infection signs, eclampsy or pre-eclampsy, difficulty of fetus removal or tocotraumatism.

Correlation was negative for gestational age and hospitalization time $(r=-0.655$-moderate $)$ : the lower the gestational age the longer the hospitalization time and was positive ( $r=0.491$-moderate) with death (Table 4). Birthweight assessment per category has demonstrated that two cases of birthweight equal or under 500 grams evolved to death, with $71.5 \%$ (five cases) of death within the birthweight range of up to 999 grams, in contrast with $21.3 \%$ (13 cases) of the survivals within the same range. All deaths occurred among the low birthweight group while among the survivors, nine were over $2500 \mathrm{~g}$. Birthweight had a positive correlation with gestational age ( $r=0.799$-strong) and with death $((r=0.409$-moderate $)$ and negative with hospitalization time (-0.620-moderate (Table 4).

Positive correlations in the death cases were also detected for hyperglicemia, hypercalcemia, convulsion, respiratory insufficiency, atelectasy (Table 4) with convulsion being the more significant condition. Infection, sepsis, septic chock, enterocolitis, pulmonary hypertension, coagulation disorders and severe malformations had no significant correlation with white cerebral matter lesion evolving to death.

Following binary logistic regression analysis, all variables remained statistically significant and in regression, after exclusion of respiratory insufficiency (step 1) and hypercalcemia (step 2), the atelectasy and hyperglicemia variables did not remain statistically significant (Table 4).

Death causes determined by Neonatologists in the death certificates were per case: a) intraventricular hemorrhage; b) sepsis by Candida; severe asphyxia with ischemic hypoxic encephalopathy; renal and respiratory failure; c) secondary respiratory failure following extensive pneumonia; d) coma (bradicardy and death), e) respiratory insufficiency; f) respiratory insufficiency; metabolic disorders and extreme prematurity; g) pulmonary hemorrhage, pneumotorax; congestive cardiac failure.

\section{Discussion}

Neonatal brain white matter lesion is a severe pathology that could lead to neurological conditions and death. This research is a pioneer study for brain white matter lesion and there are no literature data that could be compared with the current one. Nevertheless, lethality rates between $8.2 \%$ and $10.3 \%$ are considered high, demonstrating the value and severeness of these lesions in neonates.

Of the seven death cases, $42.9 \%$ had echodensity and/or complicated echolucency in contrast with $36.1 \%$ of the survivors, suggesting that evolution to brain white matter lesion is an alert signal for a higher death probability, even if this finding has not shown statistical significance, possibly because of the small number of deaths noted. But the difference of $6.8 \%$ noted among the survivors and deaths by complicated lesions should be considered clinically significant. Death did not occur among brain white matter lesion cases after the postnatal period. Theoretically, in late occurrences or following clinical insult, brain white matter lesion could be less severe because of continuous medical monitoring of the neonate, and more maturity spontaneously protecting from an unfavorable evolution.

Birthweight and gestational age correlated negatively with hospitalization time. Median hospitalization time was significantly inferior among the cases evolving to death (median of 23 days $x 50$ days in the survival group), with all deaths occurring up to 44 days. This is suggestive of: postnatal premature maturing protects from death and/or the death causes occurred early in the antenatal or perinatal period.

In relation to the first hypothesis, deaths were positively correlated with birthweight, as expected and amply demonstrated in the international $7-9$ and national literature. 10,11 Nevertheless, $85.3 \%$ of low birthweight neonates survived being equivalent to the proportions of extremely low birthweight and one death occurred among the one between 2000 to $2499 \mathrm{~g}$, a range of lower mortality risk. Other factors should have influenced evolution towards death in addition to birthweight, but in the evaluations or early neonates'history, no information of the maternal or gestational history were significantly correlated to the deaths. On the other hand, in the delivery history, Apgar score showed a positive and moderate correlation with the group evolving to death. Although $57 \%$ of the neonates in this group had their Apgar score in the 5th minute from 0 to 7 , in contrast with $21.3 \%$ of the survivors, perinatal asphyxia, as determined by the Neonatologist did not significantly correlate to death. 
A "normal" premature baby can receive a low Apgar score solely because of immaturity therefore, this score cannot be used to diagnose "asphyxia" in this population making a clinical based diagnoses difficult. ${ }^{12}$ The assumption of asphyxia was based on gestational and delivery history. Nevertheless, this study did not find significant alterations in the group with fatal evolution, consequently many asphyxiated premature with a low Apgar score did not receive this clinical diagnosis.

Only in one case, perinatal asphyxia diagnosis was registered in the death certificate probably based encephalopathy and multiple organ failure. There's suspicion of non-diagnosed asphyxia in the remaining cases. Nelson and Ellenberg 13 through the multicenter study "The National Collaborative Perinatal Project" followed up 54.000 pregnant women and their children up to seven years old and confirmed that children with birthweight under $2500 \mathrm{~g}$, low Apgar score in the first and fifth minutes, were associated with $95.7 \%$ death risk and a high rate of severe neurological disorders in the survivors. On the other hand, many premature newborns have long term neurological disorders without prior diagnosis of perinatal risk factors; therefore prematurity itself is considered as the cause. It is possible that many mild and moderate ischemic hypoxic insults are not being diagnosed because of the non-use of the Apgar score, as a predictor tool for future disorders.

Still in the delivery history, non-cephalic presentation correlated significantly with death. In this type of presentation delivery is more difficult and may lead to perinatal asphyxia, nevertheless, neonates with intrauterine suffering do not have a good movement pattern and are unable to get to the cephalic position. In both situation asphyxia could be related to the non-cephalic presentation and in this study non-cephalic presentation significantly correlated with the Apgar score.

Postnatal factors analysis pointed towards a moderate and positive correlation with death in cases of: hyperglicemia, convulsion, respiratory failure and atelectasy. In general metabolic disorders are frequent in ill premature newborns and have multiple etiologies. Possibly, hyperglicemia and hypercalcemia are coadjutants and could signal the terminal phase of these patients.

Neonatal convulsion is strongly associated to perinatal asphyxia, with ischemic hypoxic encephalopathy the principal cause of this event in the neonatal period. ${ }^{14}$ Positive correlation between convulsion and death, in neonates with asphyxic brain lesion is expected and reinforces the hypothesis that perinatal asphyxia could be the main death cause for this group.

Hyaline membrane condition is the specific pathology of prematurity, secondary to low surfactant production. The more premature the neonate the more severe the condition. The occurrence of asphyxia and infectious diseases aggravate the condition and respiratory failure is its most severe expression. On the other hand, respiratory failure aggravates clinical and neurological conditions of the neonate who suffered from asphyxia and can in itself cause postnatal anoxia. Atelectasy is commonly associated to pneumonia and respiratory failure in premature newborns with severe hyaline membranes condition. Early respiratory disconfort in premature newborns is caused by the hyaline membrane disease leading to respiratory failure.

The careful review of the medical files with the survey of 53 variables and the one by one correlation of these variables with the evolution to death are among the positive aspects of the study. Nevertheless, some aspects need to be justified: a) cases assessment occurred within an eight year period, but there was a concentration of seven deaths between 1996 and 1998. Technological and medical progress in Obstetrics and Neonatology are rapidly occurring, and many medical procedures are being changed 15 17 and that could possibly favor death toll reduction; b) the presence of absence of choriomnionitis is the second etiologic factor of brain white matter lesion in addition to asphyxia, 18,19 and in some studies determined as being the cause 10,20 and in others as being a protection factor 21 for perinatal mortality. Ascending infection is diagnosed by the anatomic pathological study of the placenta. This exam cannot be assessed in the study because it was not available in 45 cases. Nevertheless ascending infection clinical suspicion did not significantly correlate with death c) the study group size was based in only one hospital. Authors chose to use secondary data for convenience due to the lack of USc information availability in other maternity hospitals or inappropriate exam performance (inappropriate transducer, low resolution device) and d) descriptive study based on medical files information. Because this was a pioneer study, it had the objective to survey data and generate hypothesis. Therefore, an option was made for a convenience sample.

\section{Conclusions}

Hospital lethality for brain white matter lesion starting during prenatal and perinatal phases was estimated in $10.3 \%$ and the following hypothesis 
were generated: perinatal asphyxia should be the principal etiologic factor, direct and indirect (aggravating the expression of prematurity diseases and infection), of perinatal and postnatal mortality among neonates with ultrasound diagnosis of brain white substance; fifth minute Apgar score $<7$ associated to ultrasound findings of brain white matter lesion are accurate markers for perinatal asphyxia diagnosis.

\section{References}

1. Victora CG, Barros FC. Infant mortaliy due to perinatal causes in Brazil: trends, regional patterns and possible interventions. São Paulo Med J. 2001; 119: 33-42.

2. Wise PH. The anatomy of a disparity in infant mortality. Ann Rev Public Health. 2003; 24: 241-62.

3. Barros FC, Hurtly SRA, Victora CG, Kirkwood MA, Vaughan JP. Comparisons of the causes and consequences of prematurity and intrauterine growth retardation: a longitudinal study in Soutern Brazil. Pediatrics. 1992; 90: 23844.

4. Gray RH, Ferraz EM, Amorin MS, Melo LF. Levels and determinants of early neonatal mortality in Natal, Northeastern Brazil: results of a surveillance and casecontrol study. Int J Epidemiol. 1991; 20 :467-73.

5. Kuban KC, Allred EN, Dammann O, Pagano M, Leviton A, Share J, Abiri M, Di Salvo D, Doubilet P, Kairam R, Kazam E, Kirpekar M, Rosenfeld DL, Sanocka UM, Schonfeld SM. Developmental epidemiology network. Topography of cerebral white-matter disease of prematurity studied prospectively in 1607 very-low-birthweight infants. J Child Neurol. 2001; 16: 401-8.

6. Kumazaki K, Nakayama M, Sumida Y, Ozono K, Mushiake S, Suehara N, Wada Y, Fujimura M. Placental features in preterm infants with periventricular leucomalácia. Pediatrics. 2002; 109: 650-5.

7. Richardson DK, Phibbs CS, Gray JE, McMormick MC, Workman-Daniels K, Goldmann DA. Birth weight and illness severity: independent predictors of neonatal mortality. Pediatrics. 1993; 91: 969-75.

8. Larroque B, Marret S, Ancel PY, Arnaud C, Marpeu L, Super Nant K, Pierrat V, Rozé JC, Matis J, Cambonie G, Burguet A, Andre M, Kaminski M, Bréar G, The EPIPAGE Study Group. White matter damage and intraventricular hemorrhage in very preterm infants. J Pediatr. 2003; 143: $477-83$.

Recebido em 26 de setembro de 2005

Versão final apresentada em 7 de fevereiro de 2006

Aprovado em 12 de março de 2006

\section{Acknowledgements}

To CAPES for the doctorate scholarship and sandwich scholarship for training in the Southern Illinois University for the principal author. To the Academic Administration of the Psychology Course of the Ruy Barbosa Faculty for the financial, material and personal support, to the research of the Neurosciences Laboratory, Dr. Rosana Pelegrinni for her valuable discussion of neonatal aspects of the study. Dr. Kimberly Espy, Neuropsychological Laboratory, Southern Illinois University for the statistical and librariam support.

9. Wilcox AL, Skjaerven R. Birth weight and perinatal mortality: the effect of gestational age. Am J Public Health. 1992; 82: 378-82.

10. Miura E, Fiori F. Mortalidade perinatal e neonatal no Hospital de Clínicas de Porto Alegre. Rev Assoc Med Bras. 1997; 43: 35-9.

11. Lansky S, França E, Leal MC. Mortes perinatais evitáveis em Belo Horizonte, Minas Gerais, Brasil, 1999. Cad Saúde Pública. 2002; 18: 1389-400.

12. Apgar V, Holaday DA, James LS. Evaluation of the newborn infant - second report. JAMA. 1958; 168: 1985-8.

13. Nelson KB, Ellenberg JH. Apgar scores as predictors of chronic neurologic disability. Pediatrics. 1981; 68: 36-44.

14. Tharp Br. Neonatal seizures and syndromes. Epilepsia. 2002; 43 (Suppl 3): 2-10.

15. LeFlore JD, Salhb WA, Broyles S, Engles WD. Association of antenatal and postnatal dexamethasone exposure with outcome in extremely low weight neonates. Pediatrics. 2003; 110: 275-9.

16. Ingemar I, Lamont RF. An update on the controversies of tocolytic therapy for the prevention of preterm birth. Acta Obstet Gynecol Scand. 2003; 82: 1-9.

17. Meneguel JF, Guinsburg R, Myoshi MH, Peres CA, Russo RH, Kopelman BI, Camano L. Antenatal treatment with corticosteroids for preterm neonates: impact on the incidence of respiratory distress syndrome and intra-hospital mortality. São Paulo Med J. 2003; 12: 45-52.

18. Dammann O, Kuban KCK, Leviton A. Perinatal infection, fetal inflammatory response, white matter damage, and cognitive limitations in children born preterm. Mental Retard Dev Disabil Res Rev. 2002; 8: 46-50.

19. Rezaie P, Dean A. Periventricular leucomalácia, inflammation and white matter lesions within the developing nervous system. Neuropathology. 2002; 22: 106-32.

20. Jason JM. Infectious disease-related deaths of low birth weight infants, United States, 1968 to 1982. Pediatrics. 1989; 84: 296-303.

21. Kosuge S, Ohkuchi A, Minakami H, Matsubara S, Uchida A, Eguchi Y, Honma Y, Sato I. Influence of choriomnionitis on survival and morbidity in singletons live-born at $<32$ weeks of gestation. Acta Obstet Gynecol Scand. 2000; 79: $1-5$. 